\title{
Survey of Bancroftian filariasis infection in humans and Culex mosquitoes in the western Brazilian Amazon region: implications for transmission and control
}

\author{
Rodolfo Luís Korte ${ }^{[1],[2]}$, Gilberto Fontes ${ }^{[3]}$, Juliana de Souza Almeida Aranha Camargo ${ }^{[1]}$, \\ Eliana Maria Maurício da Rocha ${ }^{[3]}$, Edicarlos André Cavalcante de Araújo ${ }^{[1]}$, \\ Marcelo Zagonel de Oliveira ${ }^{[4]}$, Rafael Vital dos Santos ${ }^{[5]}$ \\ and Luís Marcelo Aranha Camargo ${ }^{[1],[6]}$
}

[1]. Departamento de Medicina, Faculdade São Lucas, Porto Velho, RO. [2]. Departamento de Medicina, Universidade Federal de Rondônia, Porto Velho, RO. [3]. Campus Centro Oeste, Universidade Federal de São João del Rei, Divinópolis, MG. [4]. Departamento de Genética, Universidade Federal do Rio Grande do Sul, Instituto Nacional de Genética Médica Populacional, Porto Alegre, RS. [5]. Laboratório de Biologia Molecular, Instituto de Ciências Biológicas, Universidade Federal de Alagoas, Maceió, AL. [6]. Instituto de Ciências Biomédicas 5, Universidade de São Paulo, Monte Negro, RO.

\begin{abstract}
Introduction: The aim of this work was to identify possible lymphatic filariasis foci in the western Brazilian Amazonian that could be established from the reports of Rachou in the 1950s. The study was conducted in three cities of the western Brazilian Amazon region - Porto Velho and Guajará-Mirim (State of Rondônia) and Humaitá (State of Amazonas). Methods: For human infection evaluation thick blood smear stained with Giemsa was used to analyze samples collected from 10pm to 1am. Polymerase chain reaction (PCR) was used to examine mosquito vectors for the presence of Wuchereria bancrofti DNA. Humans were randomly sampled from night schools students and from inhabitants in neighborhoods lacking sanitation. Mosquitoes were collected from residences only. Results: A total 2,709 night students enrolled in the Program for Education of Young Adults (EJA), and 935 people registered in the residences near the schools were examined, being 641 from Porto Velho, 214 from Guajará-Mirim and 80 from Humaitá. No individual examined was positive for the presence of microfilariae in the blood stream. A total of 7,860 female Culex quinquefasciatus specimens examined were negative by PCR. Conclusions: This survey including human and mosquito examinations indicates that the western Amazon region of Brazil is not a focus of Bancroftian filariasis infection or transmission. Therefore, there is no need to be included in the Brazilian lymphatic filariasis control program.
\end{abstract}

Keywords: Lymphatic filariasis. Bancroftian filariasis. Amazon Region. Wuchereria bancrofti. Culex quinquefasciatus.

\section{INTRODUCTION}

Lymphatic filariasis, caused by Wuchereria bancrofti, is considered a neglected disease that affects the lives of people in many endemic regions of Ásia, Latin America, and África. The parasite is transmitted by Culex quinquefasciatus, especially in socially and economically depressed communities with no sanitation systems or treated water.

Currently, more than 1.3 billion people are at risk of the disease in 72 endemic countries. Approximately $65 \%$ of those people live in southeastern Ásia and 30\% in Africa, with the remainder in other tropical areas of the world ${ }^{1-3}$. In the Americas there are active foci in Brazil, Guyana, Haiti and the

\footnotetext{
Address to: Dr. Luís Marcelo Aranha Camargo. ICB5/USP. Rua Francisco Prestes, 2827, Setor II, 76888-000 Monte Negro, RO, Brasil.

Phone: 5569 3530-2349

e-mail: spider@icbusp.org

Received 15 July 2012

Accepted 14 February 2013
}

Dominican Republic, with 12.4 million people requiring mass drug administration. Haiti accounts for the highest proportion ${ }^{2}$.

The only focus of lymphatic filariasis known in Brazil is the metropolitan area of Recife (State of Pernambuco) $)^{3}$. Cities such as Belém (State of Pará) and Manaus (State of Amazonas), in the Amazon region, and Maceió (State of Alagoas), in Northeast Brazil, have been described as endemic areas in the past. However, these foci have been extinguished and are presently kept under surveillance ${ }^{3,4}$.

In 1953, a hemoscopic survey was performed in Porto Velho, State of Rondônia, Brazil, in which 1,400 individuals were examined (12\% of the population) and $6(0.4 \%)$ were positive for $W$. bancrofti microfilariae ${ }^{5}$. However, none of these individuals was autochthonous but were, rather, migrants from areas known to be endemic at the time, such as Belém (PA) and Manaus (AM), who had been living in Porto Velho for a shorter time than the parasite's prepatent period ${ }^{5}$.

In 1953, in State of Rondonia, another hemoscopic survey was performed in Guajará-Mirim. A total of 603 individuals were examined, and only one $(0.2 \%)$ was positive for $W$. bancrofti microfilariae; however, this case was reported as not being autochthonous ${ }^{6}$. Simultaneously, a hemoscopic survey was 
performed in Humaitá (AM), but none of the 435 individuals examined was found infected ${ }^{6}$.

Porto Velho has never been an endemic area of lymphatic filariasis, unlike other Amazonian cities such as Manaus and Belém, which were foci of active filariasis transmission.

The existence of many unconfirmed reports of elephantiasis cases in Porto Velho, the lack of further epidemiological surveys after those performed by Rachou et al. ${ }^{5}$ in the 1950 s, and the high density of $C$. quinquefasciatus prompted the present research, which was conducted to examine the actual occurrence of this endemic disease in that region.

\section{METHODS}

\section{Survey of human infection/inclusion and exclusion criteria}

Individuals under the age of five years old were excluded, as the hypothesis considered that a short time of exposure to infection would not justify the examination. Individuals who refused to participate in the survey were also excluded. All remaining individuals aged five years and over participated in the survey.

The criteria used to select the places to be evaluated included areas populated earlier in the studied cities, exhibiting urban poor characteristics with respect to their infrastructure, basic sanitation, open-air sewage and houses built on wood pilings, which met the conditions required for vector growth.

\section{Study areas}

Domicile survey in the Municipality of Porto Velho: The peripheral area and older neighborhoods of Porto Velho $\left(8^{\circ} 45^{\prime}\right.$ $42.57^{\prime \prime} \mathrm{S}, 63^{\circ} 54^{\prime} 07.06^{\prime \prime} \mathrm{W}$ ) were the target areas of the study alongside the Madeira River, where there are slums and houses built on pilings. The neighborhood and residences of Porto Velho were randomly sampled. The sample size was calculated after mapping and a census of the neighborhoods by taking each dwelling as a sample unit, using an empirical prevalence of $1 \%$, a design effect for cluster surveys of 1.8 and a confidence interval of $95 \%$ calculated by OpenEpi ${ }^{7}$. In this case, the sample size was estimated as a total of 557 randomly selected dwellings and 974 individuals older than five years old. To perform the study, the selected neighborhoods were divided into seven sectors, and $1 / 3$ of the houses in each section were randomized and selected.

Domicile survey in the Municipality of Guajará-Mirim: All dwellings in the old neighborhood of Triângulo in Guajará-Mirim $\left(10^{\circ} 47^{\prime} 27.33^{\prime \prime} \mathrm{S}, 65^{\circ} 19^{\prime} 55.98^{\prime \prime} \mathrm{W}\right)$ were selected because they shared the same poor urban infrastructure characteristics as the areas of Porto Velho. The population of Triângulo was estimated to comprise 506 individuals of all ages, and a total of 214 (31.7\%) blood samples were collected. Individuals more than five years old living in the selected area participated in the survey. The sample was not randomized and was intended to comprise all the inhabitants and houses.

Domicile survey in the Municipality of Humaitá, State of Amazonas: All dwellings of the old neighborhood of Santo Antonio in Humaitá $\left(7^{\circ} 30^{\prime} 22.20^{\prime}\right.$ ' S, 63 01'37.82” W) were selected, with 80 houses featuring a similar infrastructure as those in the previously described areas and with a population of 240 inhabitants. The sample was not randomized and was intended to comprise all houses and inhabitants.

Figure 1 shows the areas of research for $W$. bancrofti in the western Amazonian region and the old and present foci of lymphatic filariasis in Brazil (Figure 1).

\section{Survey of night students}

Since evening students include mainly adolescents and young adults, the highest-risk group for bancroftosis ${ }^{8}$, and because of the parasite's nocturnal periodicity in the region", the survey was also performed in public night schools in Porto Velho, Guajará-Mirim, and Humaitá. All 23 schools, which have a total of 3,601 students in the target area, were located within the oldest risk areas of the three cities involved in the Program for Education of Young Adults (EJA). These schools provide education to any student, youth and adult older than 18. All the students who wanted to participate were included in the sample.

\section{Blood samples and diagnosis}

The blood samples were collected from $10 \mathrm{pm}$ to $1 \mathrm{am}$ in the dwellings and from 10 to $11 \mathrm{pm}$ in the schools due to the nightly periodicity of the microfilariae in the peripheral blood stream of the human hosts. The thick blood smear (TBS) method was used for the diagnosis according to the following protocol: blood collection was performed by finger prick using a disposable lancet and used for the preparation of TBS equivalent to $0.06-0.08 \mathrm{~mL}$ of blood, which were dried at room temperature. Twelve hours after being dried, the TBSs were dehemoglobinized, fixed with methanol, stained with eosin at $0.05 \%$, and then stained with Giemsa. The slides were examined under an optical microscope with an objective lens with magnifications ranging from 10 to 40X in a blinded manner by two independent examiners.

\section{Survey of mosquito infection}

Vector collection: The Culicidae captures were performed in Porto Velho, Guajará-Mirim and Humaitá in the neighborhoods of the humans who participated in this study. All the dwellings were visited and registered except locked dwellings and those whose owners refused to participate in the survey. The number of visited dwellings exceeded the originally sampled dwellings to increase the number of mosquitoes captured. An aspirator was used to collect adult mosquitoes (Castro aspirator). Ingurgitated insects were captured inside the houses from 7 to $10 \mathrm{am}$. The insects were placed inside special fine mesh cages, separated according to the collection location and date, and then taken to the laboratory. The captured C. quinquefasciatus females were selected, placed inside test tubes (five mosquitoes/tube), and frozen at $-20^{\circ} \mathrm{C}$ for further polymerase chain reaction (PCR).

Detection of $W$. bancrofti in mosquitoes by polymerase chain reaction (PCR): Briefly, genomic DNA was isolated from blood-engorged mosquitoes using the method described by Vasuki et al. ${ }^{10}$ with minor modifications. Dried mosquitoes (five per tube) were macerated with $100 \mu \mathrm{L}$ of TE buffer $(10 \mathrm{mM}$ Tris-HCl, $0.1 \mathrm{mM}$ EDTA, $\mathrm{pH} 8.0)$ and incubated at $100^{\circ} \mathrm{C}$ for $10 \mathrm{~min}$. After incubation, the DNA was isolated 


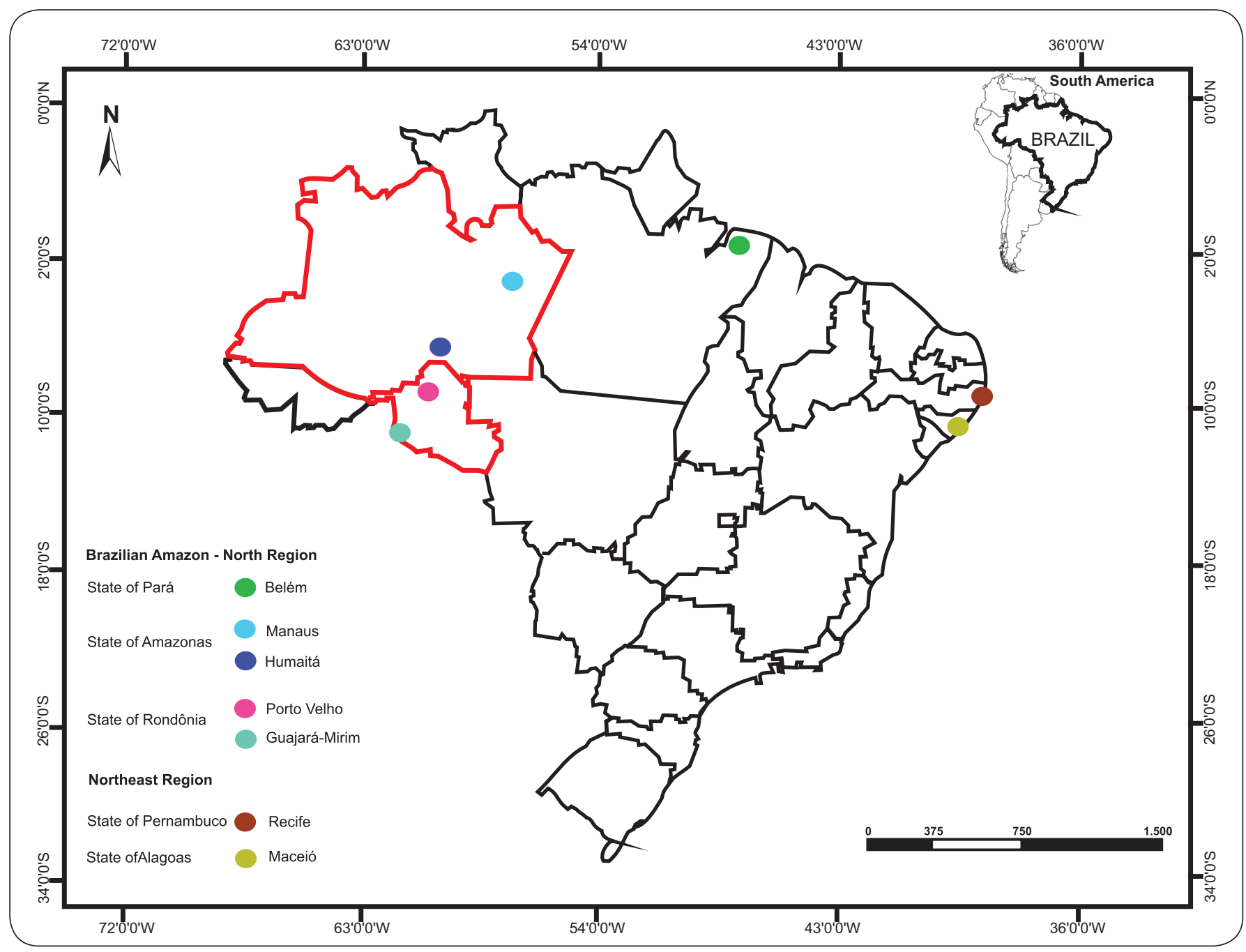

FIGURE 1 - Map showing the survey locations (Porto Velho, Guajará-Mirim and Humaitá), the old foci of lymphatic filariasis transmission where the disease has already been eliminated (Belém, Manaus and Maceió), and the only area where lymphatic filariasis transmission is still present (Recife and its metropolitan area).

using a Microcon YM-100 centrifugal filter device (millipore) according to the manufacturer's instructions, a step introduced in the original technique in order to concentrate the extracted DNA. The PCR was conducted using the primer pair NV1 (5'- CGT GAT GGC ATC AAA GTA GCG - '3) and NV2 (5'-CCC TCACTTACC ATAAGACAA- '3) to detect the 188bp target repeat fragment (SspI) of W. bancrofti (SspI; GenBank accession n. L20344) ${ }^{11}$. Conventional PCR were performed in a volume of $25 \mu \mathrm{L}$ containing $20 \mathrm{pmol}$ of each primer (NV1/NV2), $200 \mu \mathrm{M}$ deoxyribonucleotide triphosphates (dNTPs), PCR buffer $(50 \mathrm{mM} \mathrm{KCl}, 10 \mathrm{mM}$ Tris-HCl, $\mathrm{pH} 8.4), 1.5 \mathrm{mM} \mathrm{MgCl}$, ultrapure DNA-free water, $1.5 \mathrm{U} / \mu \mathrm{L}$ Taq DNA polymerase and $4 \mu \mathrm{L}$ of template DNA. All reagents were from Invitrogen ${ }^{8}$. The PCR thermal cycling (PCR Express ThermoHybaid ${ }^{\mathrm{TM}}$ ) conditions were 35 cycles of $92^{\circ} \mathrm{C}$ for $1 \mathrm{~min}, 55^{\circ} \mathrm{C}$ for $1 \mathrm{~min}$, and $72^{\circ} \mathrm{C}$ for $1 \mathrm{~min}$. The PCR amplicons were run on a $1.5 \%$ $(\mathrm{m} / \mathrm{v})$ agarose gel at $90 \mathrm{~V}$ for $1 \mathrm{~h}$, stained with ethidium bromide $(4 \mathrm{mg} / \mathrm{mL})$, and visualized under ultraviolet illumination (Vilber Lourmat ${ }^{\mathrm{TM}}$ TFX-20.M). The gels were photographed using a video documentation system (Vilber Lourmat ${ }^{\mathrm{TM}}$ DP-001 FDC) and then analyzed (photoCaptMW for Windows 10.01 Vilber Lourmat $\left.^{\mathrm{TM}}\right)$.

\section{Ethical considerations}

Every person examined signed a consent form and was well informed before being engaged in the survey, and the participation of the minors was authorized by their parents or guardians. Every person examined was able to sign his/ her name. The project was approved by the Internal Review Board (IRB) of São Lucas College on December 11, 2007, and registered under the number 143/2007 and by the REC of São Paulo University (USP).

\section{RESULTS}

\section{Human Infection}

Domicile surveys in the Cities of Porto Velho, GuajaráMirim and Humaitá: In Porto Velho, 493 houses were visited ( $88.5 \%$ of the total houses selected for inclusion), and 641 
people were surveyed ( $65.8 \%$ of the individuals in the defined area). In Guajará-Mirim, 169 houses were visited (100\% of the houses in the defined area), and 214 dwellers were examined (42.3\% of the total individuals). In Humaitá, all 80 houses of the old neighborhood of the Santo Antonio Community were visited, and 80 individuals were surveyed $(33.3 \%$ of the total individuals). In the three surveyed areas, all examined samples were negative for microfilariae (Table 1).

Night students survey: Out of 3,601 students, 2,709 were examined in the three research areas. In Porto Velho, the visits involved 11 schools in the previously defined area and included $1,684(71.1 \%)$ students. In Guajará-Mirim, all five schools in the previously defined area were visited, and $272(81.2 \%)$ students were examined. In Humaitá, all seven night schools in the previously defined area were visited, and 753 (83.6\%) students were examined (Table 2). All results were negative for microfilariae in the students blood. This study found no evidence of microfilarial infection in any of the individuals studied in all three areas (Table 2).

Survey of the infection of mosquito vectors: A total of 8,212 female mosquitoes were collected in the three target areas, with 95.8\% (7,860) being C. quinquefasciatus and $4.2 \%$ belonging to other genera, including Aedes, Psorophora and Anopheles. PCR was performed to detect the DNA of $W$. bancrofti in all C. quinquefasciatus females, but none of the mosquitoes was positive (Table 3).

TABLE 1 - Results of thick blood smear examination for Wuchereria bancrofti infection carried out among the population of three cities in the Amazon region of Brazil - 2008/2009

\begin{tabular}{|c|c|c|c|c|c|c|c|}
\hline \multirow[b]{2}{*}{ Municipalities } & \multirow{2}{*}{$\begin{array}{c}\text { Number of houses in } \\
\text { the surveyed area }\end{array}$} & \multicolumn{2}{|c|}{ Visited houses } & \multirow{2}{*}{$\begin{array}{l}\text { Number of dwellers } \\
\text { in the surveyed area* }\end{array}$} & \multicolumn{2}{|c|}{ Examined dwellers** } & \multirow{2}{*}{$\begin{array}{c}\text { Result } \\
\text { positive exams }\end{array}$} \\
\hline & & $\mathrm{n}$ & $\%$ & & $\mathrm{n}$ & $\%$ & \\
\hline Porto Velho & 557 & 493 & 88.5 & 974 & 641 & 65.8 & 0 \\
\hline Humaitá & 80 & 80 & 100.0 & 240 & 80 & 33.3 & 0 \\
\hline Total & 806 & 742 & 92.0 & 1,720 & 935 & 54.4 & 0 \\
\hline
\end{tabular}

*All ages, including children under 5 year old; **People who accepted to participate in the survey over 5 years old.

TABLE 2 - Results of thick blood smear examinations for Wuchereria bancrofti infection carried out among students older than 18 years in schools, in three cities in the Amazon region of Brazil - 2009

\begin{tabular}{lccccc}
\hline Municipalities & $\begin{array}{l}\text { Number of schools } \\
\text { enrolled in the study }\end{array}$ & $\begin{array}{l}\text { Total number } \\
\text { of students }\end{array}$ & \multicolumn{2}{c}{$\begin{array}{c}\text { Students examined } \\
\text { positive exams }\end{array}$} \\
\hline Porto Velho & 11 & 2,368 & 1,684 & 71.1 & 0 \\
Guajará-Mirim & 5 & 333 & 272 & 81.7 & 0 \\
Humaitá & 7 & 900 & 753 & 83.7 & 0 \\
\hline Total & 23 & 3,601 & 2,709 & 75.2 & 0
\end{tabular}

TABLE 3 - Results of the screening of Culex quinquefasciatus mosquitoes for Wuchereria bancrofti DNA examined by polymerase chain reaction (PCR), collected in three cities of Brazilian Amazon region - 2008/2009

\begin{tabular}{|c|c|c|c|c|c|c|c|c|c|}
\hline \multirow[b]{2}{*}{ Municipality } & \multirow{2}{*}{$\begin{array}{l}\text { Number of } \\
\text { dwellings* }\end{array}$} & \multicolumn{2}{|c|}{ Visited houses } & \multicolumn{2}{|c|}{ Houses - mosquitoes collection } & \multirow{2}{*}{$\begin{array}{c}\text { Total of female } \\
\text { mosquitoes }\end{array}$} & \multicolumn{2}{|c|}{ Culex } & \multirow{2}{*}{$\begin{array}{c}\text { Result } \\
\text { positive PCR }\end{array}$} \\
\hline & & $\mathrm{n}$ & $\%$ & $\mathrm{n}$ & $\%$ & & $\mathrm{n}$ & $\%$ & \\
\hline Porto Velho & 1,525 & 1,262 & 82.7 & 1,080 & 85.6 & 3,650 & 3,512 & 96.1 & 0 \\
\hline Humaitá & 324 & 164 & 50.1 & 156 & 84.3 & 2,583 & 2,583 & 99.6 & 0 \\
\hline Total & 2,124 & 1,687 & 79.4 & 1,464 & 86.8 & 8,212 & 7,860 & 95.8 & 0 \\
\hline
\end{tabular}

PCR: polymerase chain reaction; *Some dwellings are not in the same area of the human survey, but in the neighbohood. In this case, the study area was amplified in order to increase mosquito capture.

\section{DISCUSSION}

Since the 1960s, no survey has been performed to determine whether the vicinities of Porto Velho, Guajará-Mirim and Humaitá were or could be silent areas of lymphatic filariasis transmission. The weather conditions of these areas in Amazonas favor the transmission of $W$. bancrofti. In addition, because of its lack of basic sanitation, the known vector of the parasite was present, and autochthonous occurrences have been diagnosed in the area in the past. The aim of this study was to identify why filariasis did not develop in these areas, as found in the survey described above. 
Using the TBS method, this work studied populations settled alongside the rivers in areas favorable for the development of this parasite as well as night students, whose environment conditions were similar to those reported in studies performed in extinct foci, such as Maceió and Belém ${ }^{3}$, and Recife metropolitan region, the only remaining area of filariasis in Brazil. No occurrence or evidence of the disease was found in the studied Cities of Rondônia and Amazonas.

In the present study, the diagnostic method was the TBS, and its main limitation is a reduced sensitivity to the identification of patients affected by mild microfilaremia ${ }^{12}$. However, TBS is a rapid, practical and economic technique, commonly applied in large-scale field studies, and features good sensitivity when the parasitemia is greater than 10 microfilariae $/ \mathrm{mL}$ of blood ${ }^{12}$.

This study, as similar surveys performed in other states, endeavored to provide care to the populations that are undoubtedly subjected to higher social and environmental risk factors, that is, extremely poor areas with no basic sanitation systems and that are close to areas of higher vector proliferation. Notably, the investigated municipalities are relatively new, whereas the surveys were performed in contiguous, older areas of these cities. Poor basic sanitation conditions in habitational conglomerates are determining factors that could foster and maintain filariasis transmission. Thus, the populations exposed to higher social and environmental transmission risks were incorporated, and the likelihood of false-negative results for filariasis infection was reduced. In addition to the risk population, the present study included also participants of the Young Adult Students' program of the local State government involving 18 to 35 year old individuals enrolled in basic and mid-level schools. This categorization was chosen for operational reasons according to the studies performed previously in other areas of the country ${ }^{8,13}$. As suggested by Rocha et al. ${ }^{14}$, the prevalence of bancroftosis may occur in young age brackets, which were emphasized in this survey. Furthermore, the surveyed schools were located near those places with a higher probability of the presence of the disease, which are the oldest settlements of the cities with poor urban infrastructure.

The assessment of filariasis transmission was performed by monitoring the infection in the insect vectors by PCR. The PCR has proven to be a powerful tool to evaluate the contamination intensity of the mosquitoes in endemic areas and, because of these advantages, has replaced the conventional dissection methods for the diagnosis of $W$. bancrofti in mosquitoes ${ }^{15}$. This method, in addition to being more sensitive than dissection, enables a large number of samples to be processed in a short period.

Other factors that may have contributed to the nonproliferation of the disease may be associated with the environment, the vector itself, and the cases diagnosed and treated in the 1960s.

Regarding the environment, filariasis is known to occur in tropical and subtropical hot and humid areas. Chandra et al. ${ }^{16}$ found that the density of Culex mosquitoes decrease during rainy periods, although periods of higher temperatures and humidity favor $W$. bancrofti transmission, shortening developmental period from $L_{1}$ to $L_{3}$ (infective larva) stages of the parasite in the vector.
The studied areas of Porto Velho, Guajará-Mirim and Humaitá exhibit the characteristics that facilitate rapid development of the parasite into its infectious larval form. However, during periods of increased heat and humidity, the number of vectors decreases, although there is no synchrony between the infecting larvae and the number of vectors, and the transmission risk decreases. One of the factors that may have contributed to the nonproliferation of the disease is the lack of synchronization between the number of vectors and the environmental conditions for the development of the agent that causes the disease ${ }^{17}$.

Several vector types are involved in filariasis transmission, including mosquitoes of the genera Culex, Anopheles, Aedes and Mansonia $^{18}$. In Brazil, the only known vectors are the mosquitoes of the genus Culex, which are prevalent in the studied areas.

Studies with different filariae worms show that the vector efficiency depends on the susceptibility to pathogen infection and the microfilaria density ${ }^{19-21}$. Vectorial competence can be affected by the densities of microfilariae ingested during blood meal, and not all the blood fed mosquitoes became infected. Furthermore, when the insect is exposed to a high concentration of parasites an increased vectorial mortality rate can occur.

The non occurrence of the disease may also be associated with the blood feeding in vectors of low vectorial competence. Not all larvae ingested by the mosquitoes will survive inside the gastrointestinal tract and some of the larvae are expelled by the vector itself, whereas others are injured by the oropharyngeal tract during the repast $\mathrm{t}^{22}$. As a result, the transmission is reduced ${ }^{22}$.

Those intrinsic and extrinsic factors and the complex interactions between filarial parasites and mosquitoes, that influence vectorial competence, could be in part responsible for geographic distribution of filariasis.

Accordingly, the discussion also involves findings from the studies performed by Hairston and De Meillon ${ }^{23}$, which clearly showed that immature $W$. bancrofti larvae do not survive inside their hosts, thereby largely decreasing the load of contaminative filariae (L3) and increasing the number of bites required for infected mosquitoes to cause a parasitic infection. An estimated 15,500 infecting bites are required to cause microfilaremia ${ }^{23}$. Snow and Michael ${ }^{24}$ in 2002 and Chandra ${ }^{17}$ in 2008 also showed that the filariae present in the vector may increase the likeliness of dissemination but may also be fatal to the vector when their presence is too high by increasing the lethality, which contributes to the reduction in transmission.

Regarding the number of bites by mosquitoes infected with larvae in this survey, no individual was found to have been infected with $W$. bancrofti microfilariae by the TBS method, and no infected mosquito was found by PCR in the areas surveyed, proving the lack of foci formation in the studied areas, such as in the allochthonous cases of W. bancrofti reported in the past. In the studied areas, no focus formation was detected, even with the presence of the parasite vectors and appropriate environmental conditions. The factors that influence the probability of the vector being infected and transmitting the infection include 
the microfilarial infection of the vertebrate hosts. The mosquito infection rate is proportional to the microfilariae density in the peripheral blood stream of the patients. Brito et al. ${ }^{25}$ found that the infection rate of mosquitoes fed with the blood of individuals with mild $W$. bancrofti microfilarial infections (1-10 microfilariae $/ \mathrm{mL}$ ) was $0.07 \%$, whereas the efficiency of the vector was nearly $17 \%$. That is, for every six microfilariae ingested, only one reaches the infecting larva stage.

Several studies have demonstrated that the persistence of this endemic disease depends on the occurrence of high natural infection rates of the mosquitoes. Nevertheless, there has been no consensus among researchers that can forecast the occurrence of a new case of patent microfilarial infection in humans ${ }^{26}$. However, below a certain critical number of infecting bites, lymphatic filariasis has not been confirmed to be an endemic disease, which may be the case in this area. In places where the microfilariae density is maintained below five microfilariae $/ 60 \mathrm{~mL}$ blood, there is considered to be no transmission risk ${ }^{27}$.

In a recent study performed in Maceió it was showed that the filarial load in a patient is one of the determining factors for maintaining transmission foci ${ }^{28}$. Such a load may have been one of the factors that determined the disease dissemination in the studied areas. In Maceió, Leite et al. ${ }^{28}$ found that an individual suffering from $W$. bancrofti microfilarial infection who came from an endemic area and had been living for more than 10 years in a nonendemic area, was not capable of inducing the formation of a new bancroftosis focus, even though the new area exhibited the appropriate environmental conditions. One of the possibilities considered by the researchers was the mild microfilarial infection of the infected individual (4 microfilariae/mL of blood) ${ }^{28}$.

However, with the growing migration in the country, there is a risk that the disease might be introduced in areas free of the infection ${ }^{3}$. In Sri Lanka infected migrants have engendered lymphatic filariasis in areas where the disease was previously unknown ${ }^{29}$. This occurred also in metropolitan Recife, where cases of the parasitosis appeared in previously unaffected $\operatorname{areas}^{30,31}$

The magnitude of the potential risk for the establishment of sustainable foci of lymphatic filariasis depends mainly on the number of $W$. bancrofti carriers, the microfilarial density in these individuals, the existence of potential vectors, and environmental conditions that favor transmission ${ }^{32-34}$.

Finally, the few people suffering from $W$. bancrofti microfilarial infections found in the Cities of Porto Velho and Guarajá-Mirim in the 1950s had allochthonous, mild microfilarial infections (out of the seven people infected with parasites, five had fewer than five microfilariae per slide examined $)^{5,35}$. It appears that the small number of people infected with the parasites and the mild nature of the microfilarial infection reported in the 1950s in Porto Velho and Guarajá-Mirim were not sufficient to establish and maintain the lymphatic filariasis in the examined areas, which were considered harmless and may or may not be associated with environmental and other factors related to the vectors.

\section{ACKNOWLEDGMENTS}

The authors are especially grateful to the following for their support of this study: Dilene Morais B. da Silva, Célia Gonçalves Pereira, Beatriz Santos, and Suzane Neves Velasques. We acknowledge and give thanks to the students of São Lucas College, the population of the surveyed cities and the directors of the Program for Education of Young Adults (EJA).

\section{CONFLICT OF INTEREST}

The authors declare that there is no conflict of interest.

\section{FINANCIAL SUPPORT}

Fundação de Amparo à Pesquisa do Estado de São Paulo (FAPESP) Proj no. 2007/00848-9.

\section{REFERENCES}

1. World Health Organization. Global Programme to Eliminate Lymphatic Filariasis. Progress report on mass drug administrations in 2007. Wkly Epidemiol Rec 2008, 83:333-348.

2. World Health Organization. Global Programme to Eliminate Lymphatic Filariasis. Progress report on mass drug administration in 2010. Wkly Epidemiol Rec 2011; 86:377-388.

3. Fontes G, Leite AB, Lima ARV, Freitas H, Ehrenberg JP, Rocha EMM. Lymphatic filariasis in Brazil: Epidemiological situation and outlook for elimination. Parasit Vectors 2012; 5:272.

4. Fontes G, Braun RF, Fraiha-Neto H, Vieira JBF, Padilha SS, Rocha RC, et al. Filariose linfática em Belém, Estado do Pará, Norte do Brasil e a perspectiva de eliminação. Rev Soc Bras Med Trop 2005; 38:131-136.

5. Rachou RG, Lacerda NB, Costa A. Inquérito hemoscópico para pesquisa de microfilárias em Porto Velho, capital do território do Guaporé. Rev Bras Malariol D Trop 1954; 6:501-503.

6. Rachou RG. Distribuição geográfica das Filarioses humanas no Brasil. Rev Bras Malariol D Trop 1957; 9:79-100.

7. Dean AG, Sullivan KM, Soe MM. OpenEpi: Open Source Epidemiologic Statistics for Public Health, Version 2.3.1. [Updated 2011 June 23]. [Accessed on 2012 July 7]. Available from: www.OpenEpi.com/.

8. Fontes G, Rocha EMM, Brito AC, Antunes CMF. Lymphatic Filariasis in Brazilian Urban Area (Maceió, Alagoas). Mem Inst Oswaldo Cruz 1998; 93:705-710.

9. Fontes G, Rocha EMM, Brito AC, Fireman AT, Antunes CMF. The microfilarial periodicity of Wuchereria bancrofti in northeastern Brazil. Ann Trop Med Parasitol 2000; 94:373-379.

10. Vasuki V, Hoti SL, Sadanandane C, Jambulingam P. A simple and rapid DNA extraction method for the detection of Wuchereria bancrofti infection in the vector mosquito Culex quinquefasciatus by Ssp I PCR assay. Acta Trop 2003; 86:109-114.

11. Zhong M, McCarthy J, Bierwert L, Lizotte-Waniewski M, Chanteau S, Nutman $\mathrm{TB}$, et al. A polymerase chain reaction assay for detection of theparasite Wuchereria bancrofti in human blood samples. Am J Trop Med Hyg 1996; 54:357-363.

12. Fontes G, Rocha EMM. Wuchereria bancrofti - Filariose Linfática. In: Neves DP, Melo AL, Linardi PM, Vitor RWA, editors. Parasitologia Humana. 12 th $^{\mathrm{a}}$ ed. São Paulo: Atheneu; 2011. p. 323-333. 
13. Dreyer G, Medeiros Z, Béliz F, Vergetti G, Vergetti A, Café T, et al. Autochthonous Wuchereria bancrofti microfilaremia in the city of MaceióAlagoas-Brazil. Mem Inst Oswaldo Cruz 1991; 86:495-496.

14. Rocha EMM, Fontes G, Brito AC, Silva TRC, Medeiros Z, Antunes CMF. Filariose bancroftiana em áreas urbanas do Estado de Alagoas, nordeste do Brasil: estudo em população geral. Rev Soc Bras Med Trop 2000; 33:545-551.

15. Bockarie MJ, Fischer P, Williams SA, Zimmerman PA, Griffin L, Alpers MP, et al. Application of a polymerase chain reaction-ELISA to detect Wuchereria bancrofti in pools of wildcaught Anopheles punctulatus in filariasis control area in Papua New Guinea. Am J Trop Med Hyg 2000; 62:363-367.

16. Chandra G, Chatterjee SN, Banerjee BD, Majumdar G. Effect of seasonal variations on the development of Wuchereria larvae in Culex quinquefasciatus. Basic Appl Biomed 1997; 5:21.

17. Chandra G. Nature limits filarial transmission. Parasit Vectors 2008; 1:13.

18. Ramachandran CP. A guide to methods and techniques in filariasis investigations. Filariasis Research Officer. Inst Med Res Kuala Lumpur Bull 1970; 15:1-39.

19. Brito AC, Rocha DAM, Vila-Nova DA, Costa LG, Almeida WAP, Viana LS, et al. Prevalência da filariose canina causada por Dirofilaria immitis e Dipetalonema reconditum em Maceió, Alagoas, Brasil. Cad Saude Publica 2001; 17:1497-1504.

20. Christensen BM, Sutherland DR, Gleason LN. Defense reactions of mosquitoes to filarial worms: comparative studies on the response of three different mosquitoes to inoculated Brugia pahangi and Dirofilaria immitis microfilariae. J Invertebr Pathol 1984; 44:267-274.

21. Carvalho GA, Alves LC, Maia RT, Andrade CFS, Ramos RAN, Faustino MAG. Vector competence of Culex quinquefasciatus Say, 1823 exposed to different densities of microfilariae of Dirofilaria immitis (Leidy, 1856). Rev Bras Entomol 2008; 52:658-662.

22. Serrão ML, Labarthe N, Lourenço de Oliveira R. Vectorial competence of Aedes aegypti (Linnaeus 1762) Rio de Janeiro strain, to Dirofilaria immitis (Leidy, 1856). Mem Inst Oswaldo Cruz 2001; 96:593-598.

23. Hairston NG, Meillon MB. On the inefficiency of transmission of Wuchereria bancrofti from mosquito to human host. Bull World Health Org 1968; 38:935-941.

24. Snow LC, Michael E. Transmission dynamics of lymphatic filariasis: densitydependence in the uptake of Wuchereria bancrofti microfilariae by vector mosquitoes. Med Vet Entomol 2002; 16:e409-423.
25. Brito AC, Fontes G, Williams P, Rocha EMM. Bancroftian filariasis in Maceió, State of Alagoas, Brazil: observations on Culex quinquefasciatus after blood feeding on individuals with different densities of microfilariae in the peripheral blood stream. Am J Trop Med Hyg 1998; 58:489-494.

26. Witt C, Ottesen EA. Lymphatic filariasis: an infection of childhood. Trop Med Int Health 2001; 6:582-606.

27. Das PK, Vanamail P. Probability risk transmission matrix as a decision tool for assessing methods of transmission interruption of Wuchereria bancrofti infection. Epidemiol Infect 2007; 20:1-5.

28. Leite AB, Lima ARV, Leite RB, Santos RV, Gonçalves JEL, Rocha EMM, et al. Assessment of family and neighbors of an individual infected with Wuchereria bancrofti from a non-endemic area in the city of Maceió, Brazil. Braz J Infect Dis 2010; $14: 125-128$.

29. Organización Mundial de la Salud: Filariasis linfática: Cuarto informe del Comité de Expertos de la OMS en Filariasis. Serie de Informes Técnicos 702. Ginebra: Organización Mundial de la Salud; 1984. p.121.

30. Medeiros Z, Gomes J, Béliz F, Coutinho A, Dreyer P, Dreyer G. Screening of army soldiers for Wuchereria bancrofti infection in metropolitan Recife region Brazil: implications for epidemiologic surveillance. Trop Med Int Health 1999; 4:499-505.

31. Medeiros Z, Alves A, Brito JA, Borba L, Santos Z, Costa JP, et al. The present situation regarding lymphatic filariasis in Cabo de Santo Agostinho Pernambuco Northeast Brazil. Rev Inst Med Trop Sao Paulo 2006; 48:263-267.

32. Sutherst, RW. Global change and human vulnerability to vector-borne diseases. Clin Microbiol Rev 2004; 17:136-173.

33. Bonfim C, Alves A, Costa TR, Alencar F, Pedroza D, Portugal JL, et al. Spatial analysis and privation index to identify urban areas with a high risk of lymphatic filariasis. Trop Med Int Health 2011; 16:748-755.

34. Simonsen PE, Mwakitalu ME. Urban lymphatic filariasis. Parasitol Res 2013: 112:35-44

35. Rachou RG. Conceito e programa de profilaxia da filariose bancroftiana no Brasil. Rev Bras Malariol D Trop 1960; 12:11-40. 